\title{
Resistência anabólica e papel na atrofia como consequência de lesões: 0 papel da nutrição
}

\begin{abstract}
- O que é resistência anabólica? Resistência anabólica é principalmente responsável pela atrofia do músculo esquelético à medida que envelhecemos ou por desuso muscular durante períodos de doença ou lesão, que levam a redução da síntese proteica muscular (SPM);
\end{abstract}

- O que contribui para o quadro de resistência anabólica? Indivíduos que são resistente à insulina apresentam resistência para hiperaminocedemia. O quadro de inflamação sistêmica crônica de baixo grau está aumentada pelo envelhecimento e os marcadores inflamatórios como TNF (fator necrose tumoral alfa), PCR (proteína C-reativa), IL-6 (interleucina-6) mostram elevações significativas em obesos e pacientes em períodos de desuso. Tanto o quadro de resistência insulina e inflamação sistêmica estão relacionadas ao quadro de resistência a hiperaminocedemia;
- Mecanismos moleculares e resistência anabólica:
a. Redução da fosforalização do mTORC1
b. Atenuada digestão e absorção proteica
c. Transporte deficiente de aminoácidos para músculo e tecidos periféricos
d. Inflamação
e. Redução da fosforalização fatores de transcrição (e.g., p706SK)

- Síntese proteica muscular em indivíduos com resistência anabólica: indivíduos apresentam redução da síntese e elevada degradação de proteínas muscular no repouso e resulta em acelerada atrofia muscular;

- Células satélites e resistência anabólica: os números de células satélites nas fibras do tipo II diminuem com a idade, desuso e doença crítica, tornando-se um potencial para contribuição do quadro de resistência anabólica. Além disso, a microvasculatura (e.g. densidade) diminui com a idade e durante períodos de desuso 5 . Envelhecimento e inatividade apresentam uma diminuição nas células satélites e densidade capilares.

- Ingestão proteica e resistência anabólica: Idosos consomem em média 1,0-1,1g proteína/kg/dia divididos em $10 \mathrm{~g}$ no café da manhã, $25 \mathrm{~g}$ no almoço e $35 \mathrm{~g}$ no jantar. Idosos apresentam maior resistência anabólica comparado com jovens e precisam de $0,4 \mathrm{~g}$ proteína $/ \mathrm{kg}(30 \mathrm{~g}$ para um idoso de $70 \mathrm{~kg}$ ) para máximo estímulo SPM. Whey protein e leucina têm sido identificados como fontes mais anabólicas de proteína e aminoácido respectivamente;

- Timing protein e resistência anabólica - recomendações:
a. $1,7 \mathrm{~g} / \mathrm{kg} / \mathrm{dia}$
b. $0,40 \mathrm{~g} / \mathrm{kg}$ em bolus
c. $3 \mathrm{~g}$ leucina por refeição (4 refeições dia $)^{1}$
d. Pré-sleep

\section{- Suplementação alimentar e resistência anabólica:}

a. Creatina monoidratada: $4 \times 5 \mathrm{~g}$ durante 06 dias apresentou menor perca de força e massa muscular em indivíduos com braço engessado

b. Beta-hydroxy-beta-methylbutyrate (HMB): Indivíduos idosos (60-76 anos) receberam suplementação de $1,5 \mathrm{~g}$ duas vezes ao dia ( $3 \mathrm{~g} / \mathrm{dia})$ de HMB durante 5 dias de repouso completo na cama. $\mathrm{O}$ tratamento com HMB preveniu o declino da massa corporal magra comparado ao grupo controle. 
1. MORTON, R.W.; TRAYLOR, D.A.; WEIJS, P.J.M. et al. Defining anabolic resistance: implications for delivery of clinical care nutrition. Curr Opin Crit Care; 24(2):124-130, 2018.

2. BREEN, L.; STOKES, K.A.; CHURCHWARD-VENNE, T.A. et al. Two weeks of reduced activity decreases leg lean mass and induces "anabolic resistance" of myofibrillar protein synthesis in healthy elderly. J Clin Endocrinol Metab; 98(6):2604-12, 2013.

3. REIDY, P.T.; LINDSAY, C.C.; MCKENZIE, A.L. et al. Aging-related effects of bed rest followed by eccentric exercise rehabilitation on skeletal muscle macrophages and insulin sensitivity. Exp Gerontol; 2017.

4. NI LOCHLAINN, M.; BOWYER, R.C.E.; STEVES, C.J. Dietary Protein and Muscle in Aging People:The Potential Role of the Gut Microbiome. Nutrients; 10(7). pii: E929, 2018.

5. ARENTSON-LANTZ, E.J.; ENGLISH, K.L.; PADDON-JONES, D. et al. Fourteen days of bed rest induces a decline in satellite cell content and robust atrophy of skeletal muscle fibers in middle-aged adults. J Appl Physiol (1985); 120(8):965-75, 2016.

6. FARSIJANI, S.; MORAIS, J.A.; PAYETTE, H. et al. Relation between mealtime distribution of protein intake and lean mass loss in free-living older adults of the NuAge study. Am J Clin Nutr;104(3):694-703, 2016.

7. MOORE, D.R.; CHURCHWARD-VENNE, T.A.; WITARD, O. et al. Protein ingestion to stimulate myofibrillar protein synthesis requires greater relative protein intakes in healthy older versus younger men. J Gerontol A Biol Sci Med Sci; 70(1):57-62, 2015.

8. GORISSEN, S.H.; HORSTMAN, A.M.; FRANSSEN, R. et al. Ingestion of Wheat Protein Increases In Vivo Muscle Protein Synthesis Rates in Healthy Older Men in a Randomized Trial. J Nutr; 146(9):1651-9, 2016.

9. JOHNSTON, A.P.; BURKE, D.G.; MACNEIL, L.G. et al. Effect of creatine supplementation during cast-induced immobilization on the preservation of muscle mass, strength, and endurance. J Strength Cond Res; 23(1):116-20, 2009.

10. DEUTZ, N.E.; PEREIRA, S.L.; HAYS, N.P. et al. Effect of $\beta$-hydroxy- $\beta$-methylbutyrate (HMB) on lean body mass during 10 days of bed rest in older adults. Clin Nutr; 32(5):704-12, 2013. 